\title{
Diagnosis of Growing Pain in Bangladeshi Pediatric Population
}

\author{
Saha $\mathrm{SK}^{1}$, Modak Aditi ${ }^{2}$, Chowdhury K${ }^{3}$, Uddin $\mathrm{MS}^{4}$, Ghosh D ${ }^{5}$, Al-Mamun MA ${ }^{6}$
}

\begin{abstract}
Background: Unexplained limb pain is a major diagnostic challenge. Parents become very much worried as their physician are not sure regarding accurate diagnosis of unexplained limb pain. Majority of the limb pain are due to Growing pain which can be diagnosed by using Standard Criteria. Objectives: The purpose of the present study was to see the clinical aspects of growing pain and to determine the causes of unexplained limb pain. Methodology: This study prospectively examined the presence of growing pain in a self reported population of children with limb pain of unexplained etiology attending National Center for Control of Rheumatic Fever and Heart Disease over the period of 6 months. Results: Total 57 children of 3-12 yrs of age were enrolled in this study and out of them 43(75.4\%) were diagnosed as Growing Pain. Mean age of growing pain was $7.77(2.66) .19$ children (44.2\%) were male and 24 (55.8\%) were female. Most frequent site of pain was calf $(65.1 \%)$ and $95 \%$ cases pain occur at night. Growing Pain usually occur at slow growing period $(86 \%)$ than rapid growing period (14\%). Conclusion: Majority of unexplained limb pain are growing pain which is benign. [J Shaheed Suhrawardy Med Coll, 2013;5(1):46-48]
\end{abstract}

Keywords: Unexplained limb pain, growing pain, pediatric population

Received: March 2013; Revised: April 2013; Accepted: May 2013

\section{Introduction}

Extremity pain is a common presenting complaint of visits to pediatricians ${ }^{1-13}$. Unexplained limb pain is a major diagnostic challenge. Parents become very much worried as their physician are not sure regarding accurate diagnosis of unexplained limb pain. Majority of the limb pain are due to Growing pain which can be diagnosed by using Standard Criteria $^{7}$. The most common cause of childhood musculoskeletal pain is termed "growing pains" (GP) that exemplifies a type of non-inflammatory syndrome. These pains are much more common than all other inflammatory rheumatic diseases. The prevalence of GP ranges from 3-37\% of children. Oster found that as many as $15 \%$ of school-age children have occasional limb pain ${ }^{6}$, and recently Evans and Scutter in a very large community study in Australia reported a prevalence of $37 \%$ in children aged $4-6$ years? ${ }^{7}$. First mentioned in 1823, the pathophysiological mechanisms sourrounding its aetiology are still unknown ${ }^{14}$. GP mainly affects children between the ages of 3-12 years. GP has typical clinical characteristics; it is usually non-articular, in $2 / 3$ of children is located in the shins, calves, thighs or popliteal fossa and is almost always bilateral. The pain usually appears late in the day or is nocturnal, often awaking the child. The duration ranges from minutes to hours. The intensity can be mild or very severe. By morning the child is almost always pain free. There are no objective signs of inflammation on physical examination and laboratory investigations also normal.GP is episodic, with pain-free intervals from days to months. In severe cases the pain can occur daily. Child will have pain on days of increased activity or when the child is more moody. GP is not associated with serious organic disease, and usually resolves by late childhood. However, frequent episodes may have a major impact on the child and his family's daily routine, including absences from school and work, day time fatigue, reduced physical activity, and frequent or chronic use of pain relief medications ${ }^{15}$.

1. Dr. Santosh Kumar Saha, Junior Consultant, Department of Pediatrics, National Center for Control of Rheumatic Fever \& Heart Disease, Dhaka

2. Dr. Aditi Modak, Consultant Radiologist, Green Life Hospital Ltd., Dhaka.

3. Dr. Kamrunnahar Chowdhury, Assistant Professor, Department of Epidemiology, National Center for Control of Rheumatic Fever \& Heart Disease, Dhaka

4. Dr Md Saleh Uddin, Assistant Professor, Department of Cardiology, National Center for Control of Rheumatic Fever \& Heart Disease, Dhaka

5. Dr. Dilip Kumar Ghosh, Assistant Professor, Department of Gastroenterology, Shaheed Suhrawardy Medical College, Dhaka

6. Dr. Mohammad Abdullah Al-Mamun, Assistant Professor, Department of Surgery, Shaheed Suhrawardy Medical College, Dhaka.

\section{Correspondence}

Dr. Santosh Kumar Saha, Junior Consultant, Department of Pediatrics, National Center for Control of Rheumatic Fever \& Heart Disease, Dhaka, Bangladesh; Cell No.: +8801711890275; E-mail: santu2002@gmail.com

Conflict of interest: No conflict of interest has been declared by the authors.

Financial Support: None

Contributions by authors: All authors contributed from preparation of protocol to write up of the article. 


\section{Methodology}

This cross sectional study was conducted in National Center of Control of Rheumatic Fever \& Heart Disease, Dhaka from March 2011 to August 2011 for duration of six month. During study period all the 3-12 years old children of unexplained limb pain cases without fever and joint swelling attending National Center for Control of Rheumatic Fever \& Heart Disease who were willing to enroll in the study were the sample. Total 57 children of both sexes were collected. A checklist was used for interviewing the parents, children \& recording physical examination, anthropometric measurement and laboratory findings.

Criteria for the diagnosis of growing pains: Growing Pain was diagnosed by using Peterson \& Evans criteria ${ }^{7,10}$. There are some essential Criteria for Growing Pains which are pain in both legs, pain began between the ages of 3-12 years, pain typically occurred at the end of the day or during the night and there was no significant limitation of activity and no limping. There are some excluding factors like a pattern of pain severity not consistent with growing pains, any indication of a definite orthopaedic disorder and any abnormalities on specific testing (e.g. X-rays, bone scans, blood tests). Additional Descriptive Features of Growing Pains are pain persisted at least three months, there were periods of days, weeks or months without leg pains, pain was not a problem in the morning and there was no associated lack of well-being.

Diagnosis of other diseases was done by history, physical examination and relevant investigations. After collection, data were checked for completeness and consistencies. Statistical Package for Social Science (SPSS) for windows version 16 was Used. Descriptive statistical tests, Chi-square were used. Significance was accepted where the $p$ value $<0.05$.

\section{Results}

Out of 57 patients of unexplained limb pain, 43 were diagnosed as Growing Pain (GP), 6 were transient synovitis of hip, 2 were fibromyalgia, 4 were flat foot, legg calve perthes disease and Osgood schlater disease each was single case.

\section{Table 1: Diagnosis of Unexplained Limb Pain}

\begin{tabular}{lcc}
\hline Types of Pain & Frequency & Percent \\
\hline Growing pain & 43 & 75.4 \\
Transient synovitis of hip & 6 & 10.5 \\
Fibromyalgia & 2 & 3.5 \\
Flat foot & 4 & 7.0 \\
Legg calve perthes disease & 1 & 1.8 \\
Osgood schlatter disease & 1 & 1.8 \\
Total & $\mathbf{5 7}$ & $\mathbf{1 0 0 . 0}$ \\
\hline
\end{tabular}

Mean age of all unexplained limb pain patients was $7.77 \mathrm{yrs}$ and mean weight and height were 21.93and 117.81 respectively. Out of 57 cases of unexplained limb pain, 52.6 percent are female and rest of are male.
Table 2: Demographics of the population with or without GP

\begin{tabular}{lcc}
\hline Characteristics & With GP & Without GP \\
& N (\%) & N (\%) \\
\hline Total patients & $43(75.4)$ & $14(24.6)$ \\
Male & $19(44.2)$ & $8(57.1)$ \\
Female & $24(55.8)$ & $6(42.9)$ \\
Mean age(Yrs) & 7.4 & 8.93 \\
Mean weight $(\mathrm{Kg})$ & 21.02 & 24.71 \\
Mean height $(\mathrm{Cm})$ & 116.47 & 121.93 \\
\hline
\end{tabular}

Total Growing Pain patients were 43 and out of them 24 were female and rest of are male. The mean age, weight and height of the Growing Pain patients were $7.4 \mathrm{yrs}, 21.02 \mathrm{~kg}$ and $116.47 \mathrm{~cm}$ respectively. Patients without Growing Pain are 14 in number, 8 are male and rest of are female. Mean age, weight and height are $8.93 \mathrm{yrs}, 24.71 \mathrm{~kg}$ and 121.9 .

\section{Table 3: Location of pain}

\begin{tabular}{lcc}
\hline \multicolumn{1}{c}{ Site of Pain } & \multicolumn{2}{c}{ Responses } \\
\cline { 2 - 3 } & N & Percent \\
\hline Hip & 2 & 2.7 \\
Thigh & 5 & 6.7 \\
Popliteal & 12 & 16.0 \\
Shin & 16 & 21.3 \\
Calf & 28 & 37.3 \\
Foot & 2 & 2.7 \\
Joints & 10 & 13.3 \\
Total & $\mathbf{7 5}$ & $\mathbf{1 0 0 . 0}$ \\
\hline
\end{tabular}

In Growing Pain 95.3 percent cases pain occur at night and 44.2 percent cases at evening. 65 percent of Growing Pain patients are experience pain in calf, 37 percent in shin and 28 percent in popliteal region. 37(82.2\%) cases of Growing Pain and $8(17.8 \%)$ cases of non growing pain occur at slow growing period and only 6(50\%) cases of Growing Pain and $6(50 \%)$ cases of non growing pain occur at rapid growing period. So GP is more common in slow growing period than the non GP and it is statistically significant $(\mathrm{p}=0.02)$. In this study it can be said that GP is misnomer as it has no relation with rapid growth.

Table 4: Timing of Pain

\begin{tabular}{lcc}
\hline \multirow{2}{*}{ Pain occur } & \multicolumn{2}{c}{ Responses } \\
\cline { 2 - 3 } Evening & N & Percent \\
Night & 19 & 31.7 \\
Total & 41 & 68.3 \\
\hline
\end{tabular}




\section{Discussion}

The prevalence of GP is quite variable in different reports. Using Peterson's and Evans criteria of intermittent pain located in the lower limbs, normal physical examination, absence of laboratory abnormalities, and no limitation of activity, after the exclusion of other diseases, It was verified that two thirds of the Bangladeshi children in the sample were shown to have GP when evaluated prospectively while one third presented other causes ${ }^{16}$. Similar results are found in Brazilian Children ${ }^{14}$. Since its first description in 1823, and later, in Bennie's work in 1984, when the term "Growing Pains" was coined, the pathogenesis of GP has remained unclear ${ }^{17}$. It may be due to low pain threshold, decrease bone strength, blood perfusion changes, anatomical/mechanical factors, unhappy family environment, familial predisposition and growth15. While many of these theories such as growth, fatigue and anatomical/mechanical factors have not been supported or have been refuted, the lower pain threshold in children with GP along with the familial nature of disorder suggest that GP might be classified as a functional pain syndrome ${ }^{18}$. This report also suggests that GP is not related with growth. The mean age of GP in our study is 7.40 yrs which is the slow growing period of the children, So GP is the misnomer as it is not occur in rapid growing period. this study supports that GP is female prepondrance like other reports but why, the answer is remain unclear.

Table 5: Relation of Growing pain with Growing Period of Children

\begin{tabular}{lccc}
\hline \multirow{2}{*}{ Pain Count } & \multicolumn{2}{c}{ Age Group } & \multirow{2}{*}{ Total } \\
\cline { 2 - 3 } & $\begin{array}{c}\text { Slow growing } \\
\text { period }\end{array}$ & $\begin{array}{c}\text { Rapid growing } \\
\text { period }\end{array}$ & \\
\hline Growing pain Count & $37(82.2 \%)$ & $6(50.0 \%)$ & $43(75.4 \%)$ \\
Non growing pain Count & $8(17.8 \%)$ & $6(50 \%)$ & $14(24.6 \%)$ \\
Total Count & $\mathbf{4 5 ( 1 0 0 \% )}$ & $\mathbf{1 2 ( 1 0 0 \% )}$ & $\mathbf{5 7 ( 1 0 0 . 0 \% )}$ \\
\hline
\end{tabular}

*P value .02

\section{Conclusion}

GP is very common and easy to diagnose by peterson \& Evans criteria. Majority of unexplained limb pain are Growing Pain which is benign.

\section{References}

1. Passo MH. Aches and limb pain. Pediatr Clin North Am 1982; 29:209-21 2. Bowyer SL, Hollister JR. Limb pain in childhood. Pediatr Clin North Am 1984; 34:1053-1081

3. De-Inocencio J. Epidemiology of musculoskeletal pain in primary care. Arch Dis Child 2004; 89:431-434

4. Naish JM, Apley J. "Growing pains": a clinical study of nonarthritis limb pains in children. Arch Dis Child 1951; 26:134-140

5. Brenning R. Growing pain. Acta Soc Med Ups 1960; 65:185-201

6. Oster J, Nielson A. Growing pain: a clinical investigation of a school population. Acta Paediatr Scand 1972; 61:329-334

7. Evans AM, Scutter SD: Prevalence of "growing pains" in young children. J Pediatr 2004; 145:255-258

8. Calabro JJ, Wachtel AE, Holgerson WB, Repice MM: Growing pains: fact or fiction? Postgrad Med 1976; 59:66-72

9. Weiner SR: Growing pains. Am Fam Physician 1983; 27:189-191

10. Peterson H. Growing pains. Pediatr Clin North Am 1986; 33:1365-1372

11. Leung AKS, Robson WLM: Growing pains. Can Fam Physician 1991, 37:1463-1467

12. Manners P: Are growing pains a myth? Aust Fam Physician 1999, 28:124-127

13. Atar D, Lehman WB, Grant AD: Growing pains. Orthop Rev 1991, 20:133-136

14. Luciana Pereira et al: Diagnosis of growing pain in a Brazilian pediatric population: A prospective investigation. Einstein,2010;8(4);430-2 15. Uziel Y, Hashkes PJ. Growing Pains in Children: J Foot Ankle Research 2008;1:4-7

16. Horle B, Wood CH. Growing Pains in Children; Myth or reality? Arch Ediatr. 2008;15(8):1362-5

17. Bennie PB. Growing Pains. Arch Pediatr.1894;11:337-47

18. Mayer EA, Bushnel MC. Functional pain syndrome: Presentation and pathophysiology. 2009 (pp 431-565). Seattle: IASP Press 